\title{
Numerical Simulation Considering Non-Equilibrium Phase Change Volatile Oil Reservoir: A Case Study of Wenchang 8-3 Oil Reservoir
}

\author{
Haichun Xu \\ Hainan Branch of CNOOC Ltd., Haikou, China \\ Email: 1248541271@qq.com
}

How to cite this paper: Xu, H.C. (2021) Numerical Simulation Considering Non-Equilibrium Phase Change Volatile Oil Reservoir: A Case Study of Wenchang 8-3 Oil Reservoir. International Journal of Geosciences, 12, 834-844.

https://doi.org/10.4236/ijg.2021.129045

Received: May 26, 2021

Accepted: September 23, 2021

Published: September 26, 2021

Copyright $\odot 2021$ by author(s) and Scientific Research Publishing Inc. This work is licensed under the Creative Commons Attribution International License (CC BY 4.0).

http://creativecommons.org/licenses/by/4.0/

\begin{abstract}
As a typical volatile oil reservoir, the actual production characteristics of Wenchang 8-3 reservoir are inconsistent with the results of traditional phase equilibrium experiments. The conventional isothermal instantaneous phase equilibrium theory cannot meet the production performance or numerical simulation analysis requirements of this type of reservoir. The thermodynamic properties of volatile oil reservoirs are like those of condensate gas reservoirs. As the formation pressure drops below the dew point pressure during the mining process, the balance between the liquid phase and the gas phase is not completed instantaneously. Based on the non-equilibrium phase recovery treatment method of the condensate gas reservoir, the phase behavior change curve of the A4h well of Wenchang 8-3 oil reservoir recovered from the saturation pressure to three different pressures is analyzed. The accuracy of the numerical simulation results with or without non-equilibrium phase transition is compared. The results show that the non-equilibrium phase change has a great impact on the production performance of volatile oil reservoirs; the numerical simulation results considering the non-equilibrium phase transition are in good agreement with the actual production performance of a single well and can better reflect the actual situation of this type of reservoir. Therefore, considering the effects of non-equilibrium phase transitions has important guiding significance for the dynamic analysis of volatile oil reservoirs, numerical simulation, and the formulation of development management strategies.
\end{abstract}

\section{Keywords}

Volatile Reservoir, Production Characteristic, Non-Equilibrium Phase Change, Numerical Simulation 


\section{Analysis of Phase State and Production Characteristics of Wenchang 8-3 0il Reservoir}

\subsection{Crude Oil Composition and Phase Analysis}

Wenchang 8-3 oil reservoir is in the west of the western pearl river mouth basin, the north of the South China Sea. Three sets of volatile oil reservoirs have been developed. Wenchang 8-3 oil reservoir is in the west of the Pearl River Mouth Basin and the north of the South China Sea. Three sets of volatile oil reservoirs have been developed. Compared with the components of traditional black oil and condensate gas, the main feature of volatile oil is that the content of intermediate hydrocarbons (C2-C6) is much higher than that of black oil and condensate gas [1]. The content of light component (C1) and heavy component $(\mathrm{C} 7+)$ is between black oil and condensate gas. The fluid composition of wells WC8-3-1, A3h, and A4h in Wenchang 8-3 reservoir are calculated, shown in Table 1, and compared with the composition of typical condensate gas reservoirs and black oil reservoirs [2] [3]. It can be seen from the table that the intermediate hydrocarbons (C2-C6) of the three wells are larger than the typical condensate gas reservoirs and black oil reservoirs, while the heavy components $(\mathrm{C} 7+)$ are between the two. Therefore, the fluids in these three wells are judged to be volatile fluids.

The formation temperature of volatile oil and black oil are both on the left side of the critical point, the formation temperature of volatile oil is close to the critical point, but the formation temperature of black oil is far away from the critical point. Figure 1 is the P-T phase diagram of the A4h well fluid. It can be seen from the figure that the reservoir temperature of this well is close to and on the left side of the critical point, which conforms to the phase characteristics of typical volatile oil fluids [4]. Therefore, a comprehensive judgment: the well fluid is a volatile fluid.

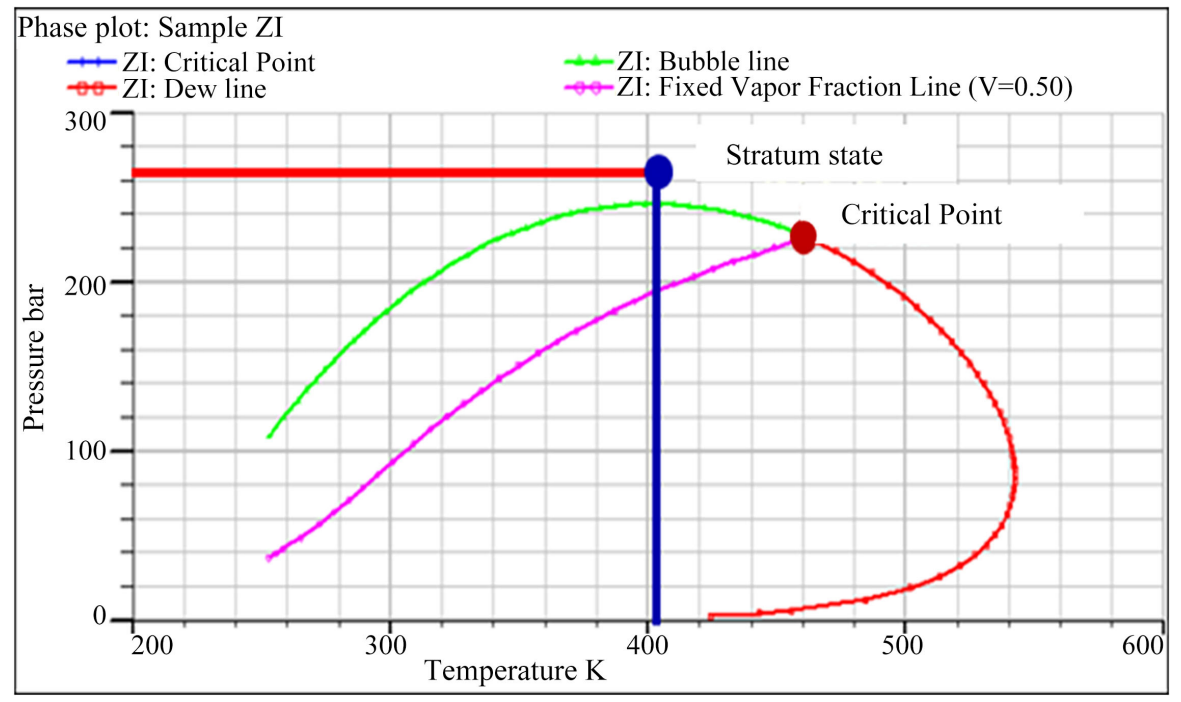

Figure 1. P-T phase diagram of well A4h fluid. 
Table 1. Comparison of fluid composition between Wenchang 8-3 reservoir and typical condensate gas, volatile oil, and black oil.

\begin{tabular}{cccccccccc}
\hline & \multicolumn{8}{c}{ fluid type } & \multicolumn{7}{c}{ hydrocarbon composition /\% } \\
\cline { 2 - 10 } & C1 & C2 & C3 & C4 & C5 & C6 & C7+ & total & C2-C6 \\
\hline $\begin{array}{c}\text { Typical } \\
\text { condensate gas }\end{array}$ & 87 & 4.30 & 2.20 & 1.60 & 0.70 & 0.50 & 3.70 & 100.00 & 9.30 \\
Typical volatile oil & 64.40 & 7.50 & 4.70 & 4.10 & 3.00 & 1.30 & 15.00 & 100.00 & 20.60 \\
Typical black oil & 48.80 & 2.80 & 1.90 & 1.60 & 1.20 & 1.60 & 42.10 & 100.00 & 9.10 \\
WC8-3-1 & 52.82 & 12.99 & 8.08 & 4.82 & 3.32 & 3.52 & 14.44 & 100.00 & 32.73 \\
A3h & 44.25 & 15.22 & 12.74 & 6.78 & 3.44 & 2.79 & 14.78 & 100.00 & 40.97 \\
A4h & 36.69 & 14.84 & 14.55 & 8.56 & 4.30 & 3.04 & 18.01 & 100.00 & 45.29 \\
\hline
\end{tabular}

\subsection{Single Well Production Characteristic Analysis}

The actual production performance characteristics of the wells in Wenchang 8-3 oil reservoir show that the volatile oil reservoirs of Wenchang 8-3 oil field are inconsistent with typical volatile oil reservoirs. When the formation pressure drops to the saturation pressure, the gas-oil ratio drops, which is inconsistent with the development characteristics of typical volatile oil reservoirs. Take Well A4h in Wenchang 8-3 oilfield as an example for analysis.

The fluid test crude oil saturation pressure of this well is $22.82 \mathrm{MPa}$. The well started production in January 2009, and its pressure (18.62 MPa) was lower than the saturation pressure in June 2012 (Figure 2). During the production process, the gas-oil ratio decreased, and the production did not show degassing characteristics (Figure 3), which was inconsistent with the phase behavior test results of the well (Figure 4). The formation pressure must be lower than the crude oil saturation pressure. Since the formation pressure around the wellbore is the largest and the fluid flow is the fastest, if degassing occurs, the fluid in the formation around the wellbore should be started first, and it will quickly migrate to the wellbore under the action of the pressure difference, causing the gas-oil ratio to rise rapidly. But this did not actually happen. There is only one situation that can explain this phenomenon, that is, the formation around the wellbore is not degassed, and the formation pressure is always higher than the saturation pressure of the crude oil [5]. The saturation pressure of crude oil decreases continuously with the exploitation to ensure that the formation pressure is always higher than the saturation pressure of crude oil. That is, volatile crude oil has a special phase change characteristic.

It can be seen from the production performance curve that, the actual gas-oil ratio of the well is lower than the gas-oil ratio $\left(550.5 \mathrm{~m}^{3} / \mathrm{m}^{3}\right)$ measured overall by the flash experiment, which is consistent with the characteristics of non-equilibrium phase change volatile oil. For this reason, for accurate numerical simulation of the well's production performance, the impact of non-equilibrium phase transitions must be considered. 


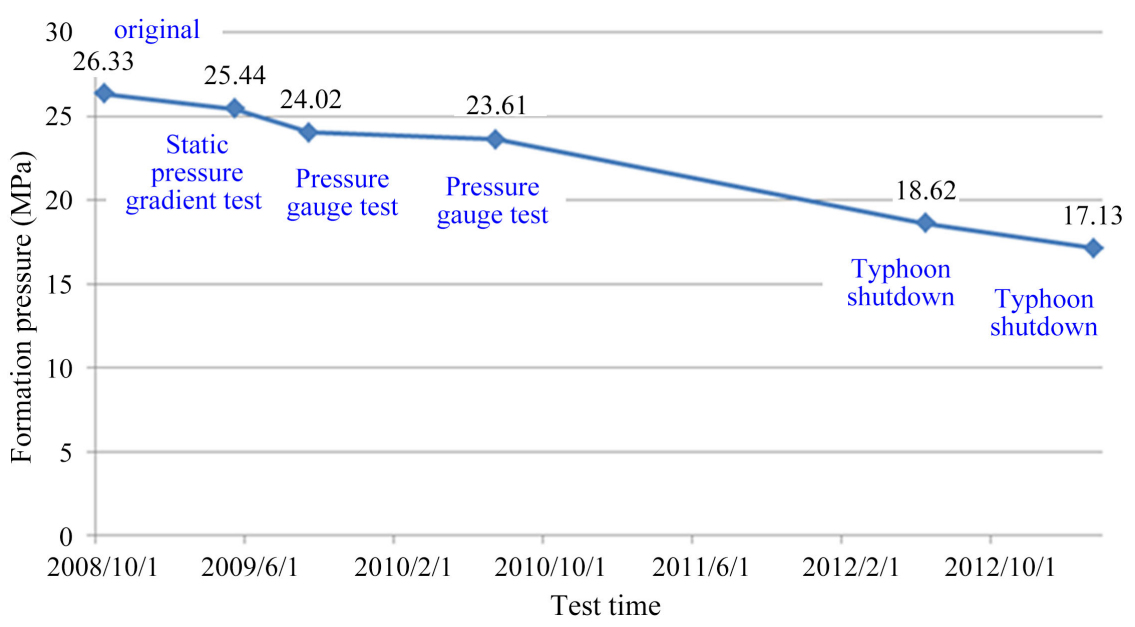

Figure 2. Formation pressure changes in Well A4h.

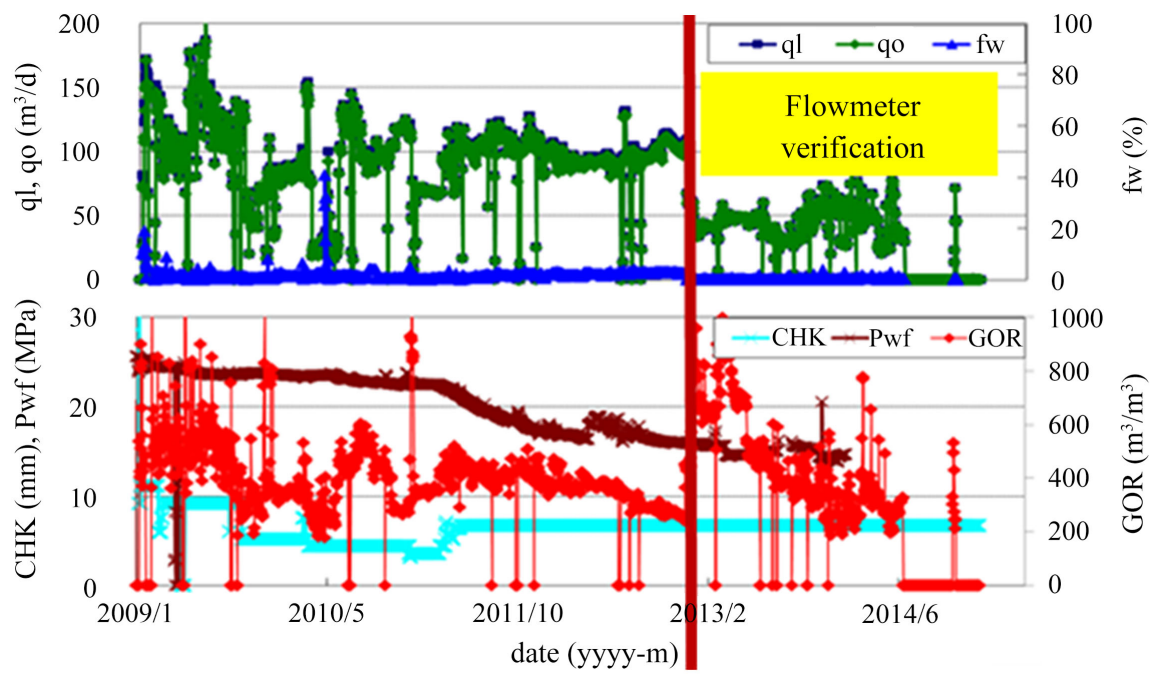

Figure 3. Production curve of Well A4h.

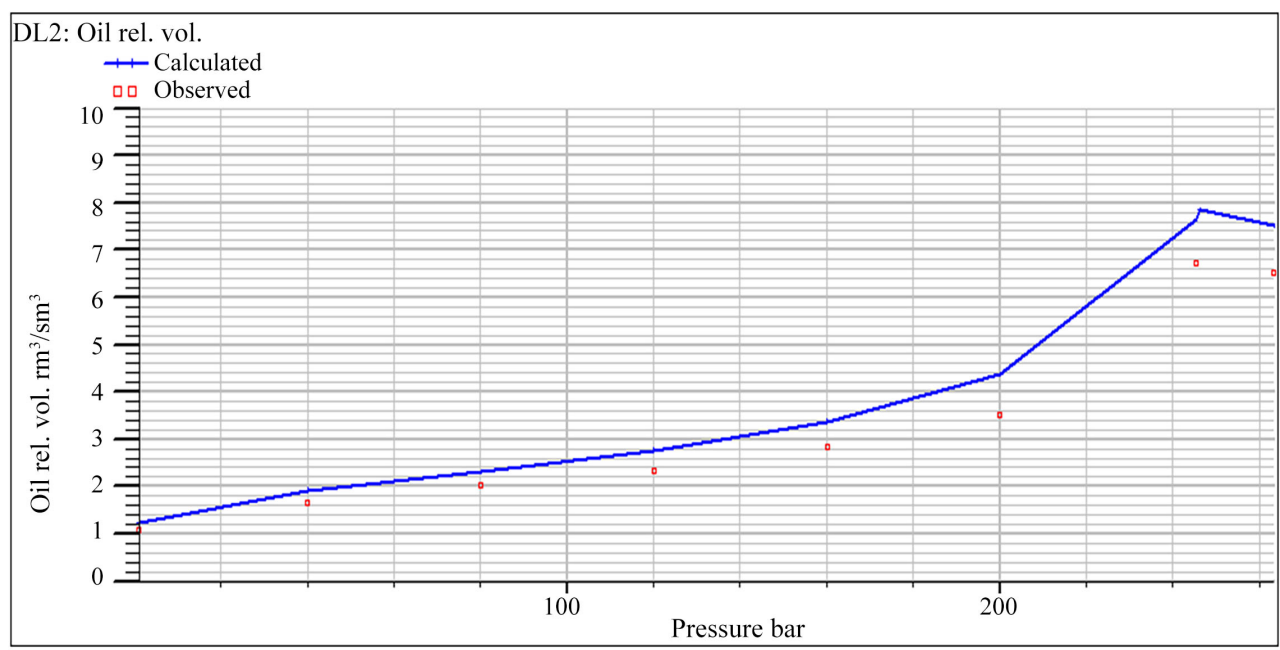

Figure 4. The relationship between dissolved gas-oil ratio and pressure in the process of multiple degassing of the A4h well fluid sample. 


\section{Numerical Simulation Processing Method of Non-Equilibrium Phase Transition}

In the early development experiment design of Wenchang 8-3 reservoir, the influence of non-equilibrium phase transition was not considered, which made the numerical simulation lack the numerical basis of non-equilibrium phase transition. In the early development experiment design of Wenchang 8-3 reservoir, the influence of non-equilibrium phase transition was not considered, which made the numerical simulation lack the numerical basis of non-equilibrium phase transition. For this reason, research is carried out based on the theory of phase recovery of condensate gas reservoir fluid. The phase state recovery is a process of restoring the phase state characteristics of the original fluid according to the phase state theory. In the general development process, the formation pressure drops, and gas is precipitated in crude oil; while in condensate gas reservoirs, condensate oil is precipitated. Knowing a point in the course of history, it is possible to perform forward and backward calculations.

Theoretical model for calculation of gas-liquid balance of formation fluid [6]:

$$
\begin{gathered}
f_{i L k}\left(P, x_{1 k}, \cdots, x_{n k}\right)-f_{i v k}\left(P, y_{1 k}, \cdots, y_{n k}\right)=0 \\
Z_{i k}-x_{i k} L_{k}-y_{i k} V_{k}=0 \\
\sum x_{i k}-\sum y_{i k}=0 \\
L_{k}+V_{k}-1=0 \\
Z_{i k}=\left[Z_{i k-1}+x_{i k-1} \Delta N_{i n k}\right] /\left(1+\Delta N_{i n k}\right)
\end{gathered}
$$

where $f_{i L k}$ and $f_{i v k}$ are the fugacity in the equilibrium liquid phase and gas phase when the component $i$ recovers at the $k$ th level respectively; $P$ is the system pressure, $\mathrm{MPa} ; Z_{i k}, X_{i k}$ and $y_{i k}$ are the mole fraction of component $i$ in the system, equilibrium liquid phase, and equilibrium gas phase when the $k$ th level is restored respectively; $L_{k}, V_{k}$ are the $k$-level recovery of the mole fraction of liquid and gas in the system; $Z_{i k-1}$ is the molar composition of component $i$ in the $k-1$ level formation (\%); $\Delta N_{\text {ink }}$ is the increment of the equilibrium oil phase under the dew point pressure when level $k$ is restored, kmol.

The following parameters can be calculated for the composition of well flow after each level of recovery [7].

1) The volume of $1 \mathrm{kmol}$ condensate gas under dew point pressure:

$$
V_{d}=Z_{d} R T_{f} / P_{f}
$$

2) Moles of well flow produced in the pressure drop process of stage J:

$$
\Delta N_{w j}=\left\{\left(Z_{v j} V_{p j}+Z_{L j} L_{p j}\right)\left(1-N_{w j-1}\right) \frac{R T_{f}}{P_{j}}-V_{d}\right\} \frac{P_{j}}{Z_{v j} R T_{f}}
$$

3) Under the $J$-level pressure, the cumulative recovery factor of the well flow when the gas production is depleted:

$$
N_{w j}=\sum_{i=2}^{j} \Delta N_{w i}
$$


4) Saturation of retrograde condensate liquid under formation pressure of $J$ level:

$$
S_{o j}=Z_{L j} L_{p j}\left(1-N_{w j-1}\right) \frac{R T_{f}}{P_{j} V_{d}}
$$

where $L_{P j}$ and $V_{P j}$ are the molar fractions of equilibrium liquid and gas phases in the formation at pressure level $; V_{d}$ and $Z_{d}$ are the volume and deviation coefficient under dew point pressure, L/kmol; $T_{f}$ and $P_{f}$ are formation temperature and pressure, $\mathrm{K}, \mathrm{MPa} ; Z_{v j} Z_{L j}$ are the deviation factor of the balance between the gas phase and the liquid phase in the formation at a pressure of level $j ; N_{w j}$ is the cumulative production volume of well fluids under $j$-level pressure, $\mathrm{kmol} ; R$ is the gas constant, $R=8.31 \mathrm{MPa} \cdot \mathrm{L} /(\mathrm{kmol} \cdot \mathrm{K})$.

The current commercial numerical simulation software (ECLIPSE, CMG, etc.) cannot simulate the non-equilibrium phase change process of fluids, and the phase change is treated as an instantaneous phase equilibrium in the simulation calculation. To effectively characterize the initial composition of the fluid, according to the "higher bubble point pressure of volatile oil", the phase recovery method was used to study the phase recovery of the oil samples from the A4h well. Three sets of fluid compositions at different saturation pressures are obtained, and the composition gradient is adopted, which approximately represents the non-equilibrium phase change effect. Based on the above-mentioned phase recovery theory, the phase status of Well $\mathrm{A} 4 \mathrm{~h}$ was recovered to different saturation pressures of 22.3, 22.0, and 16.5 MPa, respectively. The balance oil is added to obtain the change curve of the phase properties of the well when the saturation pressure of the crude oil of the well is restored to 22.3, 22.0, and 16.5 MPa (Figures 5-8). The three groups of different fluid compositions obtained after the phase state recovery are shown in Table 2 , and the state equation calculation parameters obtained after the phase state recovery are shown in Table 3.

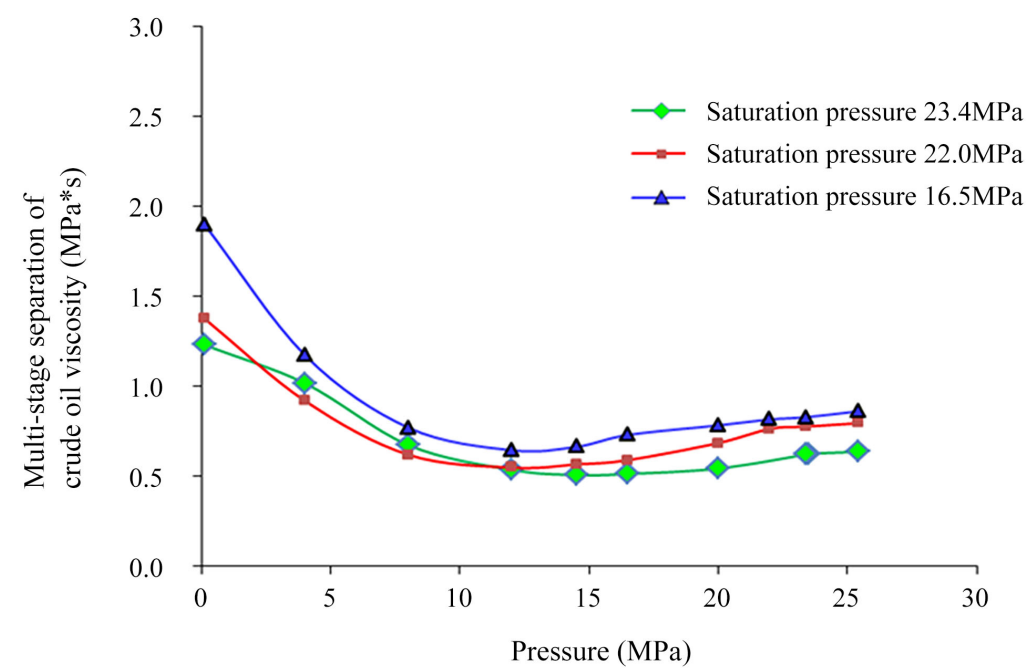

Figure 5. Comparison of the viscosity of multi-stage separated crude oil when the phase state of the oil sample in A4h well returns to different saturation pressures. 


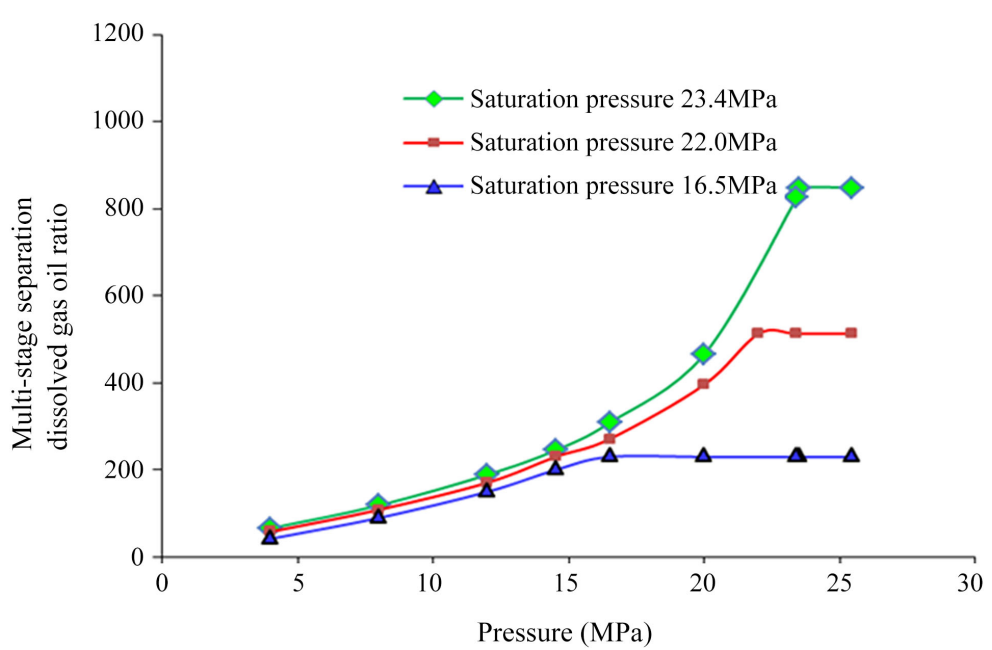

Figure 6. Comparison of the dissolved gas-oil ratio of the multi-stage separated crude oil after the phase state of the oil sample in the A4h well returns to different saturation pressures.

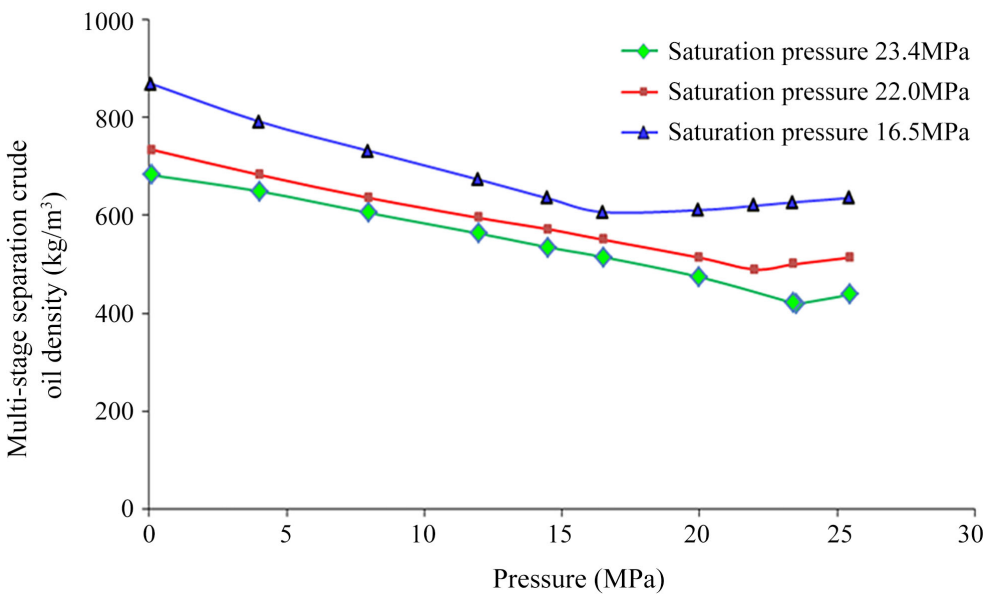

Figure 7. Comparison of the density of multi-stage separated crude oil when the phase state of the oil sample in A4h well returns to different saturation pressures.

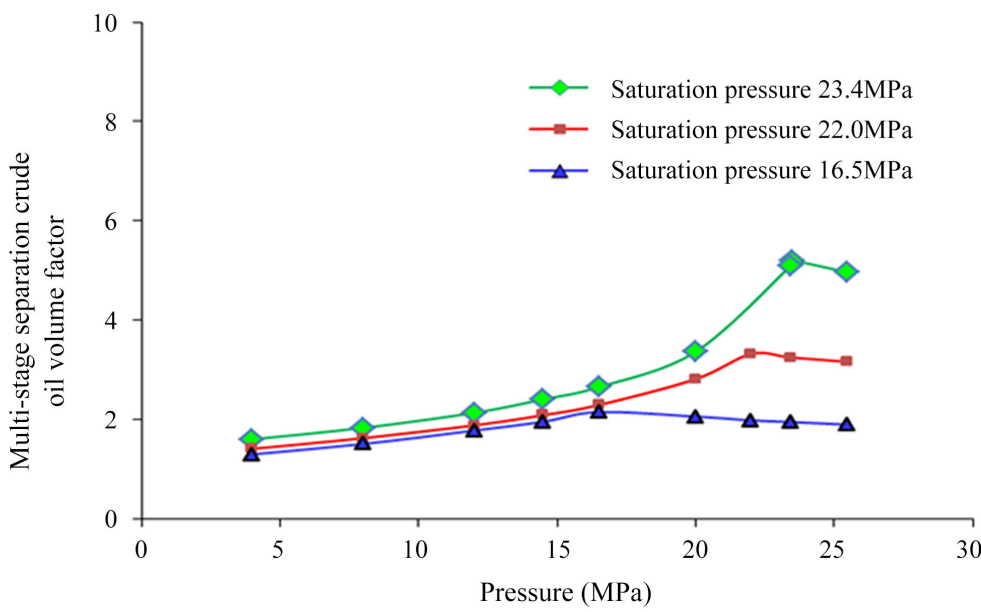

Figure 8. Comparison of the volume coefficients of multi-stage separated crude oil when the phase state of the oil sample in A4h well returns to different saturation pressures. 
Table 2. The composition of the phase state of the oil sample in A4h well restored to different saturation pressures.

\begin{tabular}{|c|c|c|c|}
\hline \multirow{3}{*}{$\begin{array}{l}\text { Composition } \\
\text { name }\end{array}$} & \multicolumn{3}{|c|}{ Well flow composition, \% } \\
\hline & Saturation pressure & Saturation pressure & Saturation pressure \\
\hline & $22.3 \mathrm{MPa}$ & $22.0 \mathrm{MPa}$ & $16.5 \mathrm{MPa}$ \\
\hline $\mathrm{X} 1+$ & 42.83 & 39.34 & 42.54 \\
\hline $\mathrm{X} 2+$ & 18.38 & 17.40 & 2.69 \\
\hline $\mathrm{C} 3+$ & 12.19 & 12.17 & 1.23 \\
\hline $\mathrm{C} 4+$ & 6.49 & 7.01 & 1.86 \\
\hline $\mathrm{C} 5+$ & 3.29 & 3.83 & 1.98 \\
\hline C6+ & 2.67 & 3.12 & 1.59 \\
\hline C14+ & 14.15 & 17.13 & 48.11 \\
\hline Total & 100.00 & 100.00 & 100.00 \\
\hline
\end{tabular}

Table 3. The parameter field of the equation of state of the volatile oil of the ZH1-1L oil group after the phase state recovery.

\begin{tabular}{cccccc}
\hline \multirow{2}{*}{ Composition } & $\begin{array}{c}\text { Molecular } \\
\text { weight }\end{array}$ & $\begin{array}{c}\text { Critical } \\
\text { pressure Pc }\end{array}$ & $\begin{array}{c}\text { Critical } \\
\text { temperature Tc }\end{array}$ & Omega A Omega B \\
\cline { 2 - 5 } X1+ & 16.18 & 45.91 & 189.88 & 0.46 & 0.08 \\
X2+ & 32.96 & 54.03 & 181.97 & 2.11 & 0.17 \\
C3+ & 44.1 & 42.46 & 206.32 & 2.11 & 0.17 \\
C4+ & 58.12 & 420.68 & 131.81 & 1.06 & 0.16 \\
C5+ & 72.15 & 1421.5 & 2.15 & 0.24 & 0.31 \\
C6+ & 84 & 1176.6 & 948.43 & 1.05 & 0.1 \\
C7+ & 193.02 & 150.89 & 1442.52 & 0.62 & 0.4 \\
\hline
\end{tabular}

\section{Application of Non-Equilibrium Phase Transition in Numerical Simulation of Wenchang 8-3 Reservoir}

Based on the above analysis, using the component model of the ECLIPSE simulation software E300, the ZH1-2L oil group A4h is numerically simulated with constant liquid volume using the unconsidered and non-equilibrium phase change processing method. Regardless of the influence of fault connectivity, composition gradients and non-equilibrium phase transitions on the simulation results, the simulation results obtained are shown in Figure 9. It can be seen from the simulation results that in March 2011, the gas-oil ratio rose sharply, the formation degassed, the corresponding formation pressure and bottom hole pressure dropped sharply, and the oil production could not be matched. As of January 2014, the gas-oil ratio increased, bottom hole pressure could not be matched, and oil production could not be matched. Before degassing, the oil production and gas-oil ratio are well fitted. However, after degassing, the simulated oil pro- 
duction decreases, the formation pressure and bottom hole pressure drop sharply, and the fitting of all indicators is poor. Therefore, Well A4h should also analyze the influence on the history matching results from the aspects of fault connectivity and non-equilibrium phase transition.

Further combining with the latest knowledge of geology, based on the data obtained by the phase recovery processing method, the composition gradient is used to approximate the characteristic parameters of the non-equilibrium phase transition [8]. The composition gradient design refers to the treatment methods of $\mathrm{M}$ volatile oil reservoir in Nigeria and Anschutz Ranch East volatile oil reservoir in the United States [9], as shown in Table 4.

According to the above processing method, after considering the non-equilibrium phase transition, the history fitting result of Well A4h is obtained, as shown in Figure 10. It can be seen from the results that the gas-oil ratio has not risen sharply, that is formation has not degassed, and the gas-oil ratio has gradually decreased; the oil production during the mining process is expected to be good; because there is no degassing phenomenon, the bottom hole pressure fitting effect is better; the change trend of the formation pressure is consistent with the actual value. This fully shows that it is necessary to consider non-equilibrium phase transitions in the numerical simulation of volatile oil reservoirs.

Table 4. ZH1-2L oil fluid pseudo-component and composition gradient.

\begin{tabular}{cccccccc}
\hline & \multicolumn{7}{c}{ Pseudo-component composition \% } \\
Altitude $/ \mathrm{m}$ & $\mathrm{X} 1+$ & $\mathrm{X} 2+$ & $\mathrm{C} 3+$ & $\mathrm{C} 4+$ & $\mathrm{C} 5+$ & $\mathrm{C} 6+$ & $\mathrm{C} 7+$ \\
\hline 2650 & 42.53 & 18.69 & 14.23 & 7.86 & 3.98 & 2.59 & 10.11 \\
2800 & 42.54 & 2.69 & 1.23 & 1.86 & 1.98 & 1.59 & 48.11 \\
\hline
\end{tabular}

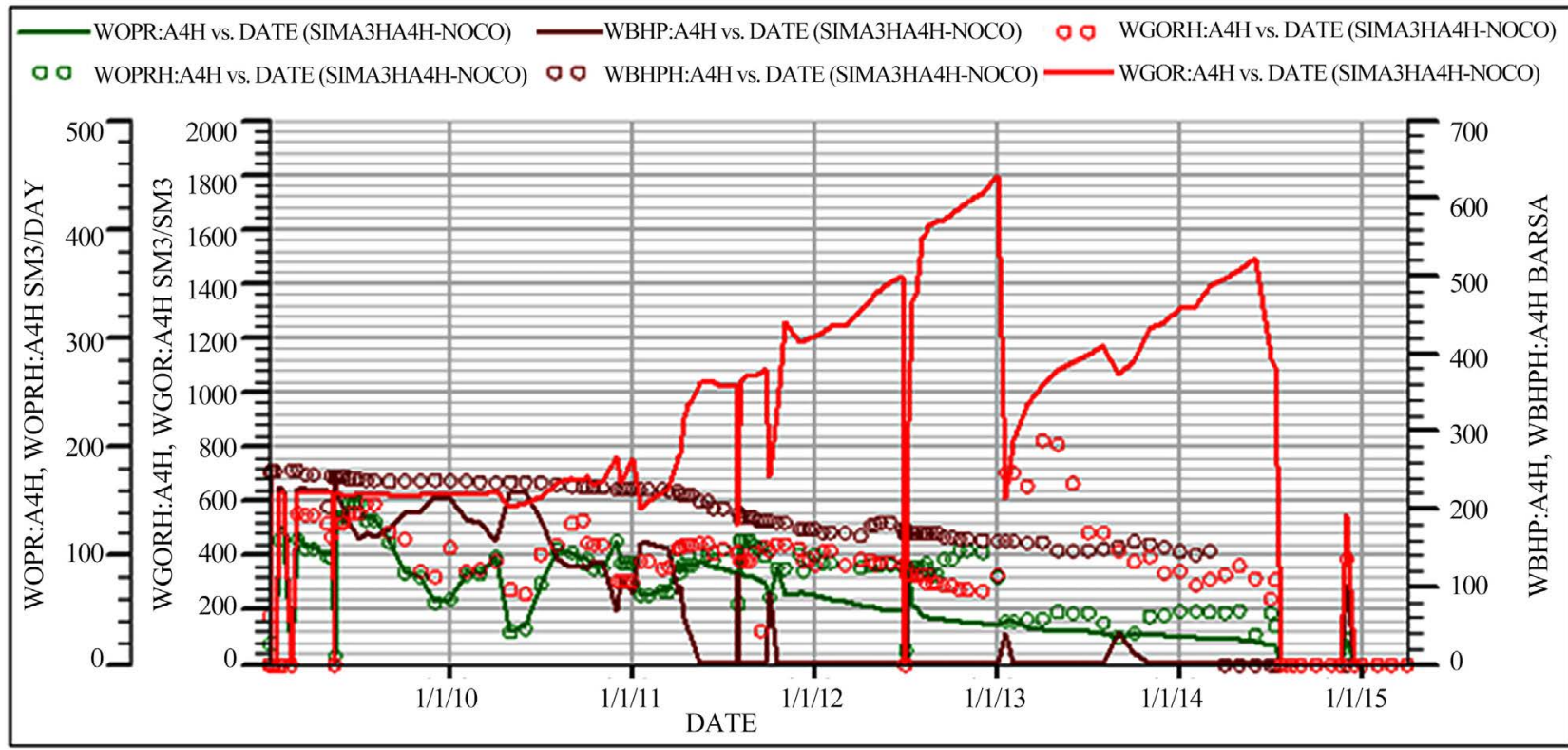

Figure 9. Production history fitting curve of Well A4h (fault connection, composition gradient and non-equilibrium phase change are not considered). 


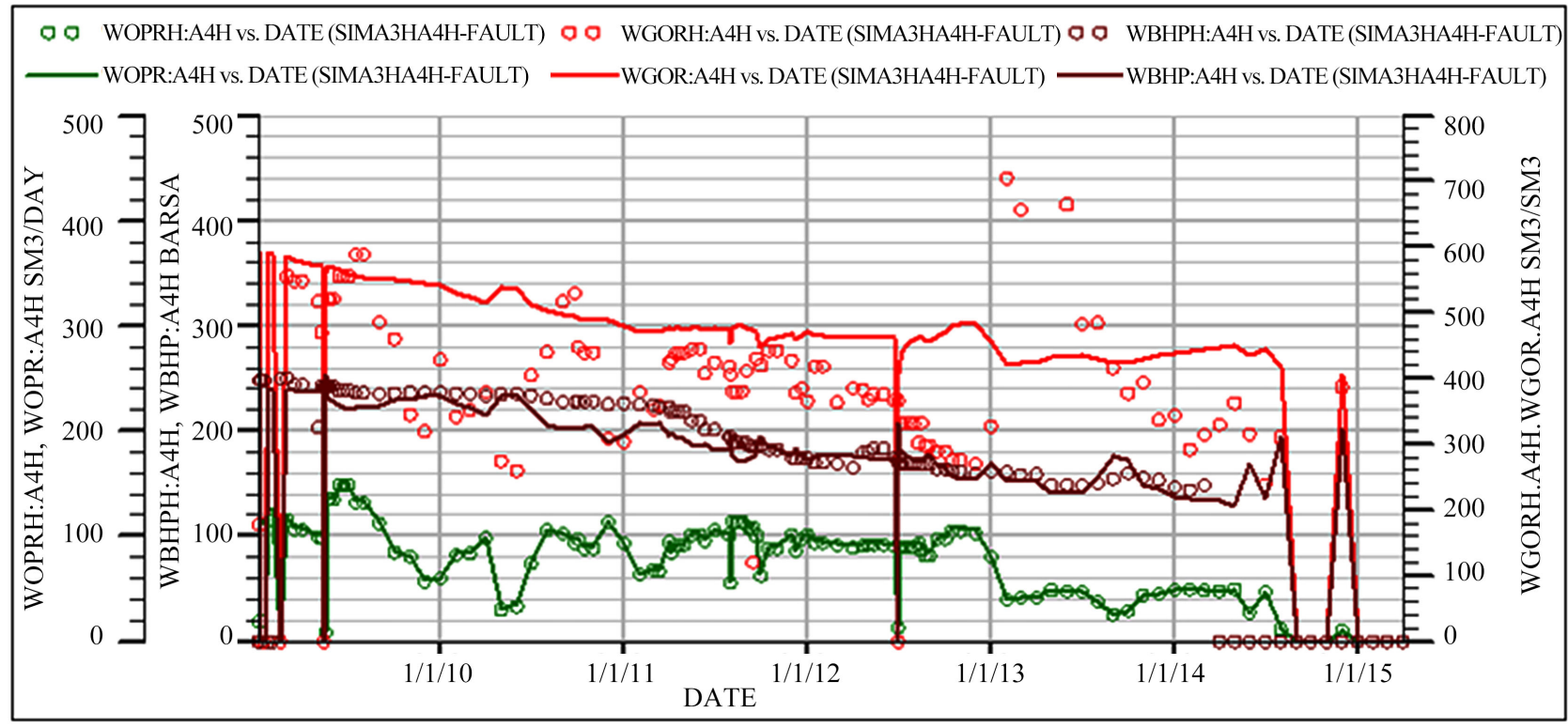

Figure 10. Production history fitting curve of Well A4h (considering composition gradient and non-equilibrium phase change).

\section{Conclusions}

1) According to the A4h well fluid composition and fluid P-T phase diagram of Wenchang 8-3 reservoir, it is comprehensively determined that the reservoir fluid has obvious volatile fluid characteristics and belongs to a volatile oil reservoir. In the phase behavior experiment results of Well A4h, the characteristics of the dissolved gas-oil ratio with pressure change are inconsistent with the actual situation, the gas-oil ratio has not risen, and the formation crude oil has not degassed, showing obvious non-equilibrium phase change characteristics.

2) Using phase recovery theory to recover the phase status of Well A4h to different saturation pressures. By adding the balance oil, the phase properties change curve and related parameters when the saturation pressure of the crude oil in Well A4h is restored to 22.3, 22.0, and $16.5 \mathrm{MPa}$ are obtained, which lays the foundation for the numerical simulation.

3) Using the ECLIPSE simulation software E300 component model, the A4h well of Wenchang 8-3 reservoir was numerically simulated with a constant liquid volume. The results show that the simulation results are consistent with the actual situation when the component gradient and non-equilibrium phase change are considered. The feasibility and reliability of numerical simulation of volatile oil reservoir considering non-equilibrium phase transition are proved.

\section{Conflicts of Interest}

The author declares no conflicts of interest regarding the publication of this paper.

\section{References}

[1] Ogunrewo, O., Herens, T. and Gringarten, A.C. (2013) Well Deliverability Fore- 
casting in Gas Condensate and Volatile Oil Wells Below Saturation Pressure. The EAGE Annual Conference \& Exhibition incorporating SPE Europec, London, June 2013, 1-13. https://doi.org/10.2118/164869-MS

[2] Liu, Y. (2015) Research for Improves Development Effection of X Volatile Oil Reservoir by Numerical Simulation. Southwest Petroleum University, Chengdu.

[3] Regueira, T., Glykioti, M.-L., Kottaki, N., Stenby, E.H., Yan, W. (2020) Density, Compressibility and Phase Equilibrium of High Pressure-High Temperature Reservoir Fluids up to $473 \mathrm{~K}$ and $140 \mathrm{MPa}$. The Journal of Supercritical Fluids, 159, Article ID: 104781. https://doi.org/10.1016/j.supflu.2020.104781

[4] Zhang, L.-M., Wang, X., et al. (2020) Phase Behavior Characteristics of Near-Critical Oil and Gas Reservoirs in Tarim Basin. Journal of Natural Gas Geoscience, 31, 1-13.

[5] Wang, C., Tang, Y., Du, Z.M., et al. (2013) Phase Behaviors of Condensate Gas with Vaporous Water and Liquid Production Characteristics in a Non-Equilibrium Pressure Drop Process. Acta Petrolei Sinica, 34, 740-746.

[6] Guo, L. and Kong, X. (2013) Phase Equilibrium Calculation of Condensate Oil and Gas Recovery Process Simulation. Oil \& Gas Storage and Transportation.

[7] Wu, K., Li, X., Wang, H., et al. (2012) A Quantitative Model for Evaluating the Impact of Volatile Oil Non-Equilibrium Phase Transition on Degassing. Petroleum EXploration \& Development, 39, 636-643. https://doi.org/10.1016/S1876-3804(12)60087-1

[8] Yang, B.Q., Yang, L., Wang, X., et al. (2013) Study of Compositional Gradient Model for Volatile Fluid Reservoir. Journal of Southwest Petroleum University: Science \& Technology Edition, 35, 145-151.

[9] Metcalfe, R.S., Vogel, J.L. and Morris, R.W. (1988) Compositional Gradients in the Anschutz Ranch East Field. SPE Reservoir Engineering, 3, 1025-1032.

https://doi.org/10.2118/14412-PA 